\title{
TICS NA APRENDIZAGEM SOB A PERSPECTIVA SOCIOINTERACIONISTA
}

\author{
TICS EN EL APRENDIZAJE BAJO LA PERSPECTIVA SOCIO- \\ INTERACCIONISTA
}

TICS IN LEARNING UNDER THE SOCIO- INTERACTIONIST PERSPECTIVE

Rodrigo Hipólito ROZA ${ }^{1}$

RESUMO: Este artigo discute o papel das Tecnologias da Informação e Comunicação (TICs) na aprendizagem, à luz da abordagem sociointeracionista. Para tanto, aborda a aprendizagem sob a perspectiva da teoria de Vygotsky, abrangendo alguns de seus conceitos-chave, o atual contexto social no qual a educação e o indivíduo encontram-se inseridos e o uso recursos tecnológicos na educação e no processo de aprendizagem. Desse modo, situa as novas tecnologias como importantes instrumentos de mediação empregados na interação do indivíduo com o meio, no contexto da sociedade da aprendizagem e do conhecimento.

PALAVRAS-CHAVE: Educação. Aprendizagem. Tecnologia da informação e comunicação. Sociedade do conhecimento e da aprendizagem. Abordagem sociointeracionista.

RESUMEN: Este artículo discute el papel de las Tecnologías de la Información y Comunicación (TIC) en el aprendizaje, a la luz del enfoque socio-interaccionista. Para ello, aborda el aprendizaje desde la perspectiva de la teoría de Vygotsky, abarcando algunos de sus conceptos clave, el actual contexto social en el que la educación y el individuo se encuentran insertados y el uso de recursos tecnológicos en la educación y en el proceso de aprendizaje. De este modo, sitúa las nuevas tecnologías como importantes instrumentos de mediación empleados en la interacción del individuo con el medio, en el contexto de la sociedad del aprendizaje y del conocimiento.

PALABRAS CLAVE: Educación. Aprendizaje. Tecnología de la información y comunicación. Sociedad del conocimiento y del aprendizaje. Enfoque sociointeraccionista.

ABSTRACT: This paper discusses the role of Information and Communication Technologies (ICTs) in learning, in the light of the socio-interactionist approach. To do so, it approaches learning from the perspective of Vygotsky's theory, covering some of its key concepts, the current social context in which education and the individual are

${ }^{1}$ Pontifícia Universidade Católica de Campinas (PUC-Campinas), Campinas - SP - Brasil. Professor do Centro de Economia e Administração (CEA). Doutor em Psicologia, Mestre em Ciência da Informação e Bacharel em Ciência da Computação. ORCID: <http://orcid.org/0000-0002-7162-4908>. E-mail: rodrigo.roza@gmail.com

RPGE- Revista on line de Política e Gestão Educacional, Araraquara, v. 22, n. 2, p. 498-506, maio/ago., 2018. ISSN: 1519-9029. DOI: 10.22633/rpge.v22.n2.maio/ago.2018.11173 
inserted and the use of technological resources in education and the learning process. In this way, it places the new technologies as important instruments of mediation used in the interaction of the individual with the environment in the context of the learning and knowledge society.

KEYWORDS: Education. Learning. Information and communication technology. Knowledge and learning society. Socio-interactionist approach.

\section{Introdução}

A educação e o indivíduo, como sujeito do processo de aprendizagem, estão inseridos em um contexto mais amplo marcado, nas últimas décadas, por profundas transformações sociais, econômicas, políticas e culturais, apoiadas fortemente nos avanços das Tecnologias da Informação e Comunicação (TICs). Tais transformações possuem impactos globais e irreversíveis, afetando sobremodo os mais diversos segmentos da sociedade. Esta nova realidade social impõe novos desafios à educação e ao indivíduo, mas também proporciona novas e diversificadas oportunidades de aprendizagem.

As transformações observadas na atual sociedade, impulsionadas em grande parte pelos avanços das TICs (LASTRES, 1999; ROZA, 2017), são relativamente recentes e extremamente dinâmicas. Em função delas, teorias amplamente aceitas e difundidas, como a teoria de Vygotsky² no campo das teorias da aprendizagem (BOCK; FURTADO; TEIXEIRA, 2001; RANGEL, 2004), encontram novos contextos e possibilidades de aplicação, demandando novos esforços e trabalhos de investigação científica.

Diante deste cenário, o presente estudo aborda o papel das TICs na aprendizagem, sob a perspectiva da abordagem sociointeracionista de Vygotsky. Neste sentido, discorre sobre alguns conceitos-chave da teoria de Vygotsky, a atual realidade social e o emprego dos recursos tecnológicos na interação do indivíduo com o meio e na consequente apropriação de informação e conhecimento.

$\mathrm{O}$ estudo do processo de aprendizagem frente às novas tecnologias na atual sociedade, tal como destacado neste artigo, mostra-se relevante à medida que busca proporcionar uma compreensão do contexto em que a educação e os sujeitos do processo de aprendizagem estão inseridos, bem como fomentar uma visão crítica sobre

\footnotetext{
${ }^{2}$ Neste texto, adotou-se a grafia Vygotsky, embora existam outras formas de grafia na literatura científica
} (MIRANDA, 2005). 
o papel desempenhado pelas TICs como instrumentos de apoio ao processo de aprendizagem.

\section{A teoria de Vygotsky}

Lev Vygotsky foi um cientista bielo-russo, que nasceu em 1896 e morreu em 1934, vítima de tuberculose, doença que o acompanhou por quatorze anos (REGO, 2012). Sua teoria é conhecida e reconhecida mundialmente, apesar de ser relativamente incompleta em função da morte precoce do autor. No Brasil, conforme apontado por Miranda (2005), suas contribuições teóricas começam a chegar, ainda de forma lenta, na segunda metade da década de 70 e a partir da década de 80 passam a ser cada vez mais citadas por educadores brasileiros.

A teoria de Vygotsky também conhecida como teoria histórico-cultural, ou sócio-histórica, do psiquismo, ou ainda abordagem sociointeracionista, tem como objetivo central "caracterizar os aspectos tipicamente humanos do comportamento e elaborar hipóteses de como essas características se formaram ao longo da história humana e de como se desenvolvem durante a vida de um indivíduo" (VYGOTSKI, 1991, p. 22). Em sua teoria, Vygotsky aborda conceitos como mediação e instrumento, signos, sistemas de símbolos, zona de desenvolvimento proximal, aprendizagem e desenvolvimento, conforme destacado por Richit (2004).

A mediação é o processo por meio do qual a ação do sujeito sobre o objeto é mediada por um elemento. Na mediação, a relação entre sujeito e objeto não é direta, mas sim feita através de um elemento intermediário. O instrumento é o elemento de mediação que age entre o sujeito e o objeto de seu trabalho. Ele amplia as possibilidades de transformação da natureza, sendo criado ou usado para atingir um determinado objetivo. Traz consigo a função para a qual foi criado, mas também outras funções de uso que foram sendo configuradas ao longo de sua história pelos grupos que o utilizaram.

Já os signos são mediadores cuja função se encontra presente na atividade psicológica, sendo também denominados instrumentos psicológicos. À medida que os signos são internalizados pelo individuo, ele realiza a criação de sistemas simbólicos, que correspondem a estruturas de signos articuladas em si, como a linguagem (VYGOTSKY, 2001), por exemplo. 
A zona de desenvolvimento proximal (ZDP), por sua vez, refere-se à "região" ou à "distância" entre o nível de desenvolvimento real, aquilo que se sabe, que já foi assimilado, e aquilo que se pode vir a aprender ou fazer com a ajuda de outras pessoas, chamado de desenvolvimento potencial (VYGOTSKI, 1991; BOCK; FURTADO; TEIXEIRA, 2001). Ela é um conceito de grande relevância na teoria de Vygotsky. Do ponto de vista da educação, é na zona de desenvolvimento proximal que deve ocorrer a intervenção pedagógica (RICHIT, 2004).

O aprendizado ou aprendizagem é o processo em que o indivíduo se apropria de informações e conhecimentos a ele apresentados através de sua interação com o meio. Ele ocorre através da internalização de signos e sistemas simbólicos pelo sujeito. Diretamente relacionado ao aprendizado está o desenvolvimento, que representa a evolução das funções psicológicas superiores. Segundo Souza e Andrada (2013), as funções psicológicas superiores, como memória, consciência, percepção, atenção, fala, pensamento, vontade, formação de conceitos e emoção, imbricam-se em uma "rede de nexos ou relações e formam, assim, um sistema psicológico, em que as funções se relacionam entre si (p.357)".

\section{O meio e o contexto social}

As teorias psicológicas de modo geral levam em consideração a interação do indivíduo com seu meio (RANGEL, 2004), fato este também observado na teoria de Vygotsky (VYGOTSKI, 1991). O meio, por sua vez, está associado a um contexto mais amplo, incluindo as esferas social, histórica e cultural presentes na abordagem sociointeracionista. Para os propósitos deste estudo, em especial, ressalta-se que esse é o contexto no qual se inserem a própria educação e também o indivíduo, como sujeito do processo de aprendizagem.

O contexto atual é marcado pelo aumento na quantidade de informação produzida e pela diminuição no tempo de disseminação dessa informação. De forma combinada, esses dois fenômenos geram elevado fluxo de informação (LE COADIC, 1996), cujos efeitos estão relacionados a uma verdadeira revolução informacional e ao surgimento de uma nova ordem mundial (ROZA, 2017).

Para designar a nova ordem mundial, diversas nomenclaturas têm sido utilizadas, dentre elas sociedade da informação, economia da informação, era da informação, sociedade do conhecimento, economia do conhecimento, era do 
conhecimento (LASTRES, 1999), sociedade da aprendizagem (COUTINHO, LISBÔA, 2011; POZO, 2004) e sociedade em rede (CASTELLS, 2005, 2010). Elas tratam da mesma realidade, mas procuram refletir preocupações e enfoques específicos de diferentes áreas do conhecimento, segundo as perspectivas e referenciais teóricos de seus autores.

Para Suaiden e Leite (2006), a nova sociedade é consequência do desenvolvimento científico na segunda metade do século $\mathrm{XX}$, com especial destaque aos avanços alicerçados no advento de novas tecnologias. Conforme apontado por Silva, Café e Catapan (2010), a atual sociedade é uma nova fase de desenvolvimento histórico, resultante de um conjunto de transformações relacionadas de forma direta à informação e à tecnologia.

$\mathrm{Na}$ perspectiva da abordagem sociointeracionista, é possível dizer que a designação sociedade do conhecimento mostra-se adequada por remeter tanto ao aspecto social como ao conhecimento. De modo similar, a designação sociedade da aprendizagem também se mostra bastante oportuna, por sua menção direta à aprendizagem. Na sociedade da aprendizagem, segundo Pozo (2004), o ato de aprender é uma exigência social cada vez maior, sendo indispensável para o desenvolvimento pessoal e cultural do indivíduo.

\section{As TICs e a aprendizagem}

No cerne das transformações observadas na sociedade da aprendizagem e do conhecimento encontram-se as TICs. Suas origens estão no desenvolvimento da informática e das telecomunicações. Na informática, o desenvolvimento ocorreu rumo a uma crescente sistematização, com o uso progressivo de software; nas telecomunicações, a evolução foi caracterizada por uma passagem do analógico para o digital (MEIRELLES, 1994) e pela convergência de voz, dados e imagem sobre uma mesma infraestrutura.

Sob a ótica da teoria de Vygotsky, os recursos de informática e telecomunicações podem ser vistos como instrumentos de mediação da aprendizagem. Portanto, além de suas funções originais, também trazem consigo as funções resultantes do seu desenvolvimento histórico. Neste sentido, tanto a sistematização da informática como a digitalização e a convergência das telecomunicações são historicamente relevantes. Contudo, atualmente mais importante que a convergência verificada no 
âmbito das telecomunicações é a convergência entre informática e telecomunicações, pois foi ela que resultou no que modernamente se denomina TICs (STEVENSON COMMITTEE, 1997).

As TICs correspondem ao conjunto de recursos tecnológicos, de informática e de telecomunicações, que apoiam o tratamento e a troca de informações. Abrangem tanto o hardware, que é a parte física dos dispositivos, como o software, que é a parte lógica suportada pelo hardware. Alguns exemplos de TICs são os computadores, os tablets, os smartphones, os sistemas operacionais, os aplicativos diversos, os bancos de dados, as redes computacionais e a Internet.

As TICs, enquanto instrumentos, possibilitam novas formas de externalização de signos e sistemas simbólicos. Além disso, também permitem a internalização de sistemas simbólicos da tecnologia e por meio dela. Observa-se que a própria linguagem, como sistema simbólico (VYGOTSKY, 2001), sofre modificações em função do uso dos instrumentos tecnológicos no processo de interação do indivíduo com o meio.

No contexto da sociedade da aprendizagem e do conhecimento, as TICs possuem aplicações em diversos ramos de atividades, como comércio, indústria, negócios em geral, entretenimento, saúde, ciência e educação. Os recursos tecnológicos atuam, de fato, como mediadores de várias ações cotidianas na atual sociedade (SILVA; CAFÉ; CATAPAN, 2010). Na educação, em particular, as novas tecnologias são aplicadas desde o uso de recursos digitais para produção e disseminação de texto, som, imagens estáticas e vídeos até a utilização de ambientes virtuais de aprendizagem (AVA), com estrutura, conteúdos e recursos tecnológicos mais abrangentes de apoio educacional.

No âmbito da educação, as TICs podem ser empregadas de maneira formal, institucionalizada. Porém, também podem usadas de modo voluntário pelos indivíduos no apoio ao seu processo de aprendizagem. Um estudo recente com universitários de administração, por exemplo, constatou que os estudantes utilizavam espontaneamente diversos recursos tecnológicos no apoio à aprendizagem, buscando escolher as tecnologias que se mostravam mais adequadas para execução de suas atividades acadêmicas (ROZA; WECHSLER, 2017).

Contudo, independentemente da aplicação das tecnologias na aprendizagem, é necessário enfatizar o ambiente cognitivo e as relações humanas e não o computador, o software ou outros recursos tecnológicos (LÉVY, 1993). É necessário ter em mente que o impacto das TICs na educação faz parte de um contexto maior, relacionado ao papel 
dessas tecnologias na sociedade (COLL; MONEREO, 2010). Por isso, as visões de tecnologias como instrumentos, entendidos conforme a concepção de Vygotsky, assim como do meio inserido um contexto social mais amplo, apresentam importantes contribuições para compreensão do processo de aprendizagem mediada pelas tecnologias.

Além disso, cabe destacar que, para a abordagem sociointeracionista, é importante considerar a zona de desenvolvimento proximal, inclusive para realização de intervenção pedagógica. Logo, o uso das tecnologias deve respeitar o nível de desenvolvimento real e o desenvolvimento potencial do indivíduo. Verifica-se também que, na abordagem sociointeracionista, a aprendizagem corresponde à apropriação de informação e conhecimento pelo indivíduo através de sua interação com o meio. Neste sentido, as novas tecnologias propiciam diversificadas formas de acesso à informação e construção de conhecimento que outrora não existiam.

Por fim, é importante salientar que na concepção da teoria de Vygotsky, "o indivíduo se desenvolve à medida que interage com o meio e com os outros indivíduos através do movimento de internalização e externalização (dialética) de signos e sistemas de símbolos e sofre as interferências desse meio (RICHIT, 2004, p.7)". Quando um indivíduo utiliza um recurso tecnológico, como um determinado software instalado em um computador, por exemplo, esse recurso é um instrumento e age como mediador entre o sujeito e o objeto de seu trabalho. Assim, o indivíduo externaliza signos e sistemas simbólicos em suas atividades ou representações, bem como internaliza sistemas simbólicos dessa tecnologia e por meio dessa tecnologia, apropriando-se de informações e conhecimentos através do processo de aprendizagem.

\section{Considerações finais}

Este estudo abordou o papel das TICs na aprendizagem, sob a perspectiva da abordagem sociointeracionista. Assim, confrontou alguns conceitos-chave explorados por Vygotsky com elementos do atual contexto social, fortemente apoiado nas novas tecnologias.

Dentre os conceitos da abordagem sociointeracionista, foram destacadas as concepções de mediação, instrumento, signos, sistemas de símbolos, zona de desenvolvimento proximal, aprendizagem e desenvolvimento. $\mathrm{O}$ atual contexto social, denominado sociedade da aprendizagem ou do conhecimento, foi apresentado como a 
realidade mais ampla em que se insere o meio com o qual o indivíduo interage durante o processo de aprendizagem.

Mesmo tendo sido elaborada em um período em que as TICs eram inexistentes, a teoria de Vygotsky mostra sua aplicabilidade em situações de aprendizagem envolvendo o uso de tecnologias, no âmbito da atual realidade social. Sob sua óptica, as TICs podem ser vistas como instrumentos de mediação entre o indivíduo e o objeto de seu trabalho. Por meio delas, os indivíduos ampliam suas possibilidades de interação, compreensão e transformação da realidade que os cerca, utilizando-se de novas formas de apropriação da informação e do conhecimento, cuja essência remete ao próprio conceito de aprendizagem.

\section{REFERÊNCIAS}

BOCK, A. M. B.; FURTADO, O.; TEIXEIRA, M. L. T. Psicologias: uma introdução ao estudo da psicologia. São Paulo: Saraiva, 2001.

CASTELLS, M. A Sociedade em Rede: do Conhecimento à Política. In: CASTELLS, M.; CARDOSO, G. (Orgs.). A Sociedade em Rede: Do Conhecimento à Acção Política. Lisboa: Imprensa Nacional - Casa da Moeda, 2005.

CASTELLS, M. The rise of the network society: The information age: Economy, society, and culture. Oxford: Wiley-Blackwell., 2010.

COLL, C.; MONEREO, C. Psicologia da Educação Virtual: aprender e ensinar com as tecnologias da informação e da comunicação. Porto Alegre: Artmed, 2010.

COUTINHO, C. P.; LISBÔA, E. S. Sociedade da informação, do conhecimento e da aprendizagem: desafios para educação no século XXI. Revista de Educação, v. 18, n. 1, p. 5-22, 2011.

LASTRES, H. M. M. Informação e conhecimento na nova ordem mundial. Ciência da Informação, v. 28, n. 1, 1999.

LE COADIC, Y. A Ciência da Informação. Brasília: Briquet de Lemos, 1996.

LÉVY, P. As Tecnologias da Inteligência: o futuro do pensamento na Era da Informática. Rio de Janeiro: Editora 34, 1993.

MEIRELLES, F. S. Informática: novas aplicações com microcomputadores. 2. ed. São Paulo: Makron Books, 1994.

MIRANDA, M. I. Conceitos centrais da teoria de Vygotsky e a prática pedagógica. Ensino em Re-Vista, v. 13, n. 1, p. 7-28, 2005. 
POZO, J. I. A sociedade da aprendizagem e o desafio de converter informação em conhecimento. Pátio: Revista Pedagógica, n. 31, p. 8-11, 2004.

RANGEL, A. P. Psicologia da Educação: Teorias de Aprendizagem. Porto Alegre: Editora da UFRGS, 2004.

REGO, T. C. Vygotsky: uma perspectiva histórico-cultural da educação. Petrópolis: Editora Vozes, 2012.

RICHIT, A. Implicações da Teoria de Vygotsky aos Processos de Aprendizagem e Desenvolvimento em Ambientes Mediados pelo Computador. Revista Perspectiva, v. 28, n. 103, p. 21-32, 2004.

ROZA, R. H.; WECHSLER, S. M. O uso das tecnologias da informação e comunicação por estudantes universitários de Administração. Competência - Revista da Educação Superior do Senac-RS, v. 10, n. 2, p. 1-7, 2017.

ROZA, R. H. Revolução informacional e os avanços tecnológicos da informática e das telecomunicações. Ciência da Informação em Revista, v. 4, n. 3, p. 03-11, 2017.

SILVA, E. L.; CAFÉ, L.; CATAPAN, A. H. Os objetos educacionais, os metadados e os repositórios na sociedade da informação. Ciência da Informação, v. 39, n. 3, p. 93 $104,2010$.

SOUZA, V. L. T.; ANDRADA, P. C. Contribuições de Vigotski para a compreensão do psiquismo. Estudos de Psicologia (Campinas), v. 30, n. 3, p. 355-365, 2013.

SUAIDEN, E.; LEITE, C. Dimensão social do conhecimento. In: TARAPANOFF, K. (Org.). Inteligência, informação e conhecimento. Brasília: Unesco; Ibict, p. 99-114, 2006. Disponível em: <http://livroaberto.ibict.br/handle/1/465>. Acesso em: 07 jan. 2017.

STEVENSON COMMITTEE. Information and communications technology in UK schools: An independent enquiry (The Stevenson Report). 1997.

VYGOTSKI, L. S. A formação social da mente. São Paulo: Martins Fontes, 1991.

VYGOTSKY, L. S. Pensamento e linguagem. eBooksBrasil, 2001. Disponível em: <http://www.ebooksbrasil.org/adobeebook/vigo.pdf>. Acesso em: 27 fev. 2018.

\section{Como referenciar este artigo}

ROZA, Rodrigo Hipólito. TICs na aprendizagem sob a perspectiva sociointeracionista. Revista on line de Política e Gestão Educacional, Araraquara, v. 22, n. 2, p. 498-506, maio/ago., 2018. ISSN: 1519-9029. DOI: 10.22633/rpge.v22.n2.maio/ago.2018.11173

Submetido em: 07/03/2018

Revisões Requeridas: 26/04/2018

Aprovado em: 07/06/2018 